\title{
Muscularity and Attractiveness as Predictors of Human Egalitarianism
}

Michael E. Price ${ }^{\mathrm{a}}$, Jinsheng Kang ${ }^{\mathrm{b}}$, James Dunn ${ }^{\mathrm{a}}$ \& Sian Hopkins ${ }^{\mathrm{a}}$

\author{
${ }^{\mathrm{a}}$ Department of Psychology, School of Social Sciences, Brunel University, Uxbridge, \\ Middlesex, UB8 3PH, UK \\ ${ }^{\mathrm{b}}$ School of Engineering and Design, Brunel University, Uxbridge, Middlesex, UB8 3PH, UK
}

\section{Corresponding author:}

Michael E. Price

Email: michael.price@brunel.ac.uk

Phone: +44 (0)1895 266974

Fax: +44 (0)1895 269724 


\begin{abstract}
In ancestral human environments, muscularity and height (in males) and physical attractiveness (in both sexes) would theoretically have correlated positively with one's social status, and thus with one's ability to benefit from social inequality. We therefore hypothesized that individuals who are more characterized by these traits would be less egalitarian (i.e., less likely to believe that resources should be distributed equally in social groups). We used a white-light 3D body scanner to extract anthropometric measurements from 118 participants, and our four egalitarianism measures included social dominance orientation and social value orientation. We found that as hypothesized, muscularity and waist-chest ratio in males, and self-perceived attractiveness in both sexes, tended to associate significantly in the predicted directions with the four egalitarianism measures; most of these correlations were of medium size. Neither height, nor two anthropometrically-assessed attractiveness measures (volume height index and waist-hip ratio), associated significantly with any egalitarianism measure in either sex. Egalitarianism has crucial social repercussions (e.g. taxes, welfare, civil rights), and results from the current study shed light on its origins.
\end{abstract}

Keywords: equality; egalitarianism; muscularity; attractiveness; social dominance orientation; social value orientation; evolutionary psychology 
Muscularity and Attractiveness as Predictors of Human Egalitarianism ${ }^{1}$

\section{Introduction}

An individual is egalitarian to the extent that he or she believes that social status and other resources should be distributed equally within social groups. From an evolutionary psychological perspective, individuals should be less egalitarian when they possess traits that, in ancestral groups, would have allowed them to gain fitness advantages via social inequality. In particular, traits which enhance one's social status should inspire others to treat one relatively well (Sell, Tooby \& Cosmides, 2009), and thus allow one to benefit more from inequality.

Some evidence supports the view that status associates negatively with egalitarianism. For example, higher-income and better-educated citizens tend to support governments that are more oriented towards competition as opposed to equality (Ritzman \& TomaskovicDevey, 1992; Kunovich \& Slomczynski, 2007), and members of ethnic majorities and higherincome individuals tend to approve of social inequality, that is, to be relatively high in "social dominance orientation” (Pratto, Sidanius, \& Levin, 2006).

There are also several biological traits that are (or ancestrally were) related to status, and that thus constitute promising candidates as predictors of egalitarianism. These traits could enhance status by improving one's ability either to inflict costs on others (e.g., by increasing one's aggressive formidability), or to confer benefits to others (e.g., by increasing one's mate value) (Sell et al., 2009). One such trait is male upper body strength, which would have enhanced the formidability and hence status of ancestral males (von Rueden, Gurven \& Kaplan, 2008). Stronger males believe that they deserve better treatment than others (Sell et

\footnotetext{
${ }^{1}$ Abbreviations: $\mathrm{SDO}=$ social dominance orientation, $\mathrm{SVO}=$ social value orientation, $\mathrm{SP}$ attractiveness $=$ selfperceived attractiveness, $\mathrm{VHI}=$ volume height index, $\mathrm{WCR}=$ waist-chest ratio, $\mathrm{WHR}=$ waist-hip ratio.
} 
al., 2009), which suggests that they may exhibit low egalitarianism in general. Second is testosterone, which associates positively with strength, aggression, and status-seeking (Burnham, 2007), and so which might be expected to correlate negatively with egalitarianism. However, ultimatum game studies on the testosterone-egalitarianism relationship have generated mixed findings, variously reporting this relationship to be negative in men (Zak et al., 2009), positive in women (Eisenegger, Naef, Snozzi, Heinrichs \& Fehr, 2010), and non-significant in men (Burnham, 2007). Third, male height may correlate positively with formidability and cognitive ability and is associated with high status (Case \& Paxson, 2008; von Rueden et al., 2008), and so should in theory negatively predict egalitarianism. Fourth, physical attractiveness, which may have been associated ancestrally with health and biological quality in both sexes and with fertility in females, is associated in modern environments with a diverse variety of social advantages (Grammer, Fink, Møller \& Thornhill, 2003). Attractiveness should in theory correlate negatively with egalitarianism in both sexes, but while people who rate themselves as attractive do tend to think they deserve better treatment than others (Sell et al., 2009), attractiveness has shown no consistent relationship with egalitarian economic game behavior (Mulford, Orbell, Shatto \& Stockard, 1998; Solnick \& Schweitzer, 1999; Takahashi, Yamagishi, Tanida, Kiyonari \& Kanazawa, 2006). Fifth, fluctuating asymmetry (the extent of difference between an individual's leftand right-side bilateral traits), which is believed to relate negatively to developmental stability and biological quality (Polak, 2003) should in theory associate negatively with status and so positively with egalitarianism. Indeed, a positive association has been found between bodily asymmetry and egalitarian economic game behavior in males (Zaatari \& Trivers, 2007).

There are also at least three theoretical reasons to predict higher egalitarianism in women than in men. First, because variance in reproductive success is greater among men, 
ancestral men had a greater incentive to engage in intrasexual competition (Darwin, 1871;

Trivers, 1972). Second, men tend to be the higher-status sex cross-culturally (Pratto et al., 2006). Finally, selection may have designed women to be relatively prosocial, to assist them in caring for offspring and in building networks of social support (Baron-Cohen, 2008).

Many studies do suggest that human females tend to prefer equal outcomes while males tend to prefer competition (review in Croson \& Gneezy, 2009), and that females have lower social dominance orientation (Pratto et al., 2006). However, other studies suggest that female economic game behavior is as egalitarian as that of males (Eckel \& Grossman, 2002; Solnick, 2001).

The current study aimed to shed new light on egalitarianism by investigating its relationships with muscularity, height, and several indicators of physical attractiveness. We expected to find negative relationships between egalitarianism and muscularity in males, height in males, and attractiveness in males and females. We also predicted that females would be more egalitarian than males. Our research was enhanced through use of a 3D body scanner, which allowed for efficient and accurate extraction of the anthropometric measurements that some variables required.

\section{Method}

One-hundred eighteen adults (56 males, mean age 22.66 \pm 4.61 years; 62 females, mean age $21.31 \pm 4.40$ years), mostly undergraduates at an English University, participated in the study in exchange for participation pool credit and/or a copy of their 3D body scan. After completing a questionnaire to measure egalitarianism and self-perceived attractiveness, participants changed into standardized, scanner-appropriate clothing (briefs and for females, a sports bra), and were body-scanned with an NX12 scanner, manufactured by $\mathrm{TC}^{2}$ (Cary, North Carolina, USA). This scanner uses white-light to create a 3D model of the body, and 
can generate hundreds of anthropometric measurements. According to the manufacturer, the scanner's point accuracy is $<1 \mathrm{~mm}$, and its circumferential accuracy is $<3 \mathrm{~mm}\left(\mathrm{TC}^{2}, 2010\right)$. Our scanning procedure was similar to that described in Brown et al. (2008). Participants stood erect in a standardized pose during the scan, without flexing any muscles, and with arms straightened and held slightly away from the sides the body. Two scans were obtained

from each participant. For each trait, the two measurements were first used to assess repeatabilities, and were then averaged to produce the single measurement used to create predictors. Repeatabilities (intraclass correlation coefficients) for all traits ranged from .940 to .998 .

\subsection{Predictor Variables}

There were six predictors. Five of these were anthropometric predictors based on body scanner measurements, taken in millimeters. The first of these, upper body muscle mass ("muscularity"), was the summed z-scores of mean bicep circumference, horizontal shoulder circumference, and chest circumference.

Second, height to the top of the head was measured by stadiometer in centimeters with footwear off.

The three remaining anthropometric predictors were all traits that have been associated with attractiveness in previous research. The first of these was waist-hip ratio (WHR, narrowest waist circumference divided by widest hip circumference); lower female WHR is regarded as more attractive by males in many cultures (Singh, 1993, 2002). Second was waist-chest ratio (WCR, narrowest waist circumference divided by widest chest circumference); females tend to be attracted to male torsos with low WCRs (Maisey, Vale, Cornelissen \& Tovee, 1999; Swami \& Toveé, 2005). Third was volume height index (VHI, body volume divided by chin height squared); VHI was found by Fan, Liu, Wu and Dai 
(2004) to be an excellent predictor of female attractiveness (and more predictive than a similar measure, body mass index).

Finally, self-perceived attractiveness ("SP attractiveness") was the response, on a nine-point scale from "very unattractive" to "very attractive", to the item "please tick the box indicating how physically attractive you think you are, in general”.

\subsection{Outcome Variables}

Four questionnaire measures were used to assess degree of (in)egalitarianism. For three of them, participants responded on a nine-point scale from "strongly disagree" to "strongly agree". The first was social dominance orientation (SDO), a measure of preference for social inequality. Our SDO measure was the mean response to items 1, 3, 4, 7, 13 and 14 (Cronbach's $\alpha=.71$ ) from the $\mathrm{SDO}_{5}$ (Sidanius \& Pratto, 1999). Sample items were "Some groups of people are just more deserving than others" and "All humans should be treated equally" (reverse-coded). Second, we measured competitiveness (on the assumption that it involves a preference for unequal outcomes) by taking the mean response to three items from the Revised Competitiveness Index (Houston, Harris, McIntire \& Francis, 2002): "I am a competitive individual", "I find competitive situations unpleasant" (reverse coded), and "I often try to out-perform others" (Cronbach's $\alpha=.68$ ). Third was a measure we call "worthiness", which was based on an "entitlement" scale used in Sell et al. (2009) to measure the extent to which one feels entitled to special treatment. "Worthiness" was the mean response to three "entitlement" items that directly capture the concept of inegalitarianism: "I deserve more than the average person", "I don't deserve more than anyone else" (reverse coded), and "I am better than most people" (Cronbach's $\alpha=.70)$. (We used abbreviated versions of the above scales because constraints on our lab time imposed a need to maximize 
efficiency, and because some "entitlement" items are not directly related to the concept of egalitarianism, e.g., "people get too upset with me when I do minor things").

Our final outcome variable was social value orientation (SVO) (Messick \& McClintock, 1968), a measure of resource sharing preferences. We measured SVO via a standard decomposed games technique (Van Lange, Otten, De Bruin, \& Joireman, 1997) in which participants are presented with nine scenarios in which they must choose how to divide a resource between self and other; they can divide it (a) equally (the "prosocial" strategy), (b) to maximize their own profit (the "individualistic" strategy), or (c) to maximize their advantage over other (the "competitive" strategy). Participants who make at least six consistent choices across all scenarios are classified according to their preferred strategy.

\section{Results}

\subsection{Social Dominance Orientation, Worthiness, and Competitiveness}

Correlations for all continuous study variables (i.e., excluding SVO) are shown separately for males and females in Table 1. All predictions were directional, so all reported $p$ vales (throughout this paper) are 1-tailed.

In males, as predicted, muscularity and SP attractiveness correlated significantly positively with SDO, worthiness and competitiveness, and WCR correlated significantly negatively with competitiveness. Contrary to predictions, WCR did not correlate significantly with SDO or worthiness, and height did not correlate significantly with any egalitarianism measure.

In females, as predicted, SP attractiveness correlated significantly positively with worthiness, and marginally positively $(p=.06)$ with competitiveness. Contrary to predictions, SP attractiveness did not correlate significantly with SDO, and VHI and WHR did not correlate significantly with any egalitarianism measure. 
In males, because multiple predictors correlated significantly with egalitarianism, multiple regression was used to determine predictors' independent effects on outcome variables. Table 2 shows the results of three separate multiple regression models, in which SDO, worthiness and competitiveness are respectively regressed on all predictors that were expected to correlate significantly with male egalitarianism. As Table 2 shows, muscularity explained significant unique variance in egalitarianism in all three models, SP attractiveness did so in two models, WCR did so in one model, and height did so in no model.

Based on the results presented in Table 2, a more efficient multiple regression model was created for each egalitarianism measure, which retained predictors that explained significant unique variance in that measure, and excluded those that did not. For SDO, the more efficient model retained muscularity and SP attractiveness as predictors (total $R^{2}=.18$, $p=.004)$; for worthiness, the more efficient model also retained muscularity and SP attractiveness as predictors (total $R^{2}=.23, p<.001$ ); and for competitiveness, the more efficient model retained muscularity and WCR as predictors (total $R^{2}=.20, p=.001$ ). In each of these three models, the two predictors each continued to explain significant unique variance in the egalitarianism measure, after controlling for the affects of age on that measure.

\subsection{Social Value Orientation}

As is typical with SVO, there were more "prosocials" $(N=49)$ and "individualists" $(N$ =34) than "competitors" $(N=15)$ (20 participants did not make six consistent choices and so could not be categorized). Therefore, competitors and individualists were combined into a single inegalitarian category, that could be compared with an egalitarian category consisting of prosocials only. We used logistic regression in order to analyze the predictors' effects on SVO, with inegalitarian category members coded as 0 , and egalitarian category members 
coded as 1. Results of this analysis are presented in Table 3. In males, as predicted, egalitarian SVO related significantly positively to WCR, and significantly negatively to muscularity. Contrary to predictions, SVO did not relate significantly to SP attractiveness or height.

In females, as predicted, egalitarian SVO related significantly positively to SP attractiveness. Contrary to predictions, SVO was not significantly related to VHI or WHR.

As muscularity and WCR were both significantly associated with SVO in males, we assessed their independent effects via multiple logistic regression. A significant amount of unique variance in SVO was explained by both muscularity $(B=-0.41, \mathrm{SE}=0.18$, Wald $=$ $5.16, p=.012)$ and $\operatorname{WCR}(B=17.55, \mathrm{SE}=8.69, \mathrm{Wald}=4.08, p=.022)$, and the two predictors together explained a medium-to-large amount of significant variance in SVO $\left(R^{2}=\right.$ .18 [Cox \& Snell], $R^{2}=.24$ [Nagelkerke], model $\left.\chi^{2}[2]=9.48, p=.004\right)$. Neither SP attractiveness nor height explained additional significant variance in SVO, beyond what muscularity and WCR already explained. Controlling for age had no affect on the ability of muscularity and WCR to explain significant variance in SVO.

\subsection{Sex Differences in Egalitarianism}

Independent $t$-tests confirmed the predictions of higher SDO scores in males $(M=$ $3.49, S D=1.54)$ than in females $(M=3.03, S D=1.32), t(116)=1.76, \mathrm{p}=.040$, higher worthiness scores in males $(M=4.31, S D=1.87)$ than in females $(M=3.74, S D=1.72)$, $t(116)=1.73, \mathrm{p}=.043$, and higher competitiveness scores in males $(M=6.32, S D=1.69)$ than in females $(M=5.60, S D=1.71), t(116)=2.29, \mathrm{p}=.012$. However, among participants who were categorized in terms of SVO, while fewer males $(47 \%)$ than females $(53 \%)$ were categorized as egalitarian, this difference was not significant according to Pearson's chisquare, $\chi^{2}(1)=0.37, p=.272$. 


\section{Discussion and Conclusions}

From an evolutionary psychological perspective, traits that would have increased one's social status in ancestral environments should decrease one's preference for social equality in modern environments. The results presented above offer some support for this perspective by suggesting three traits as relevant predictors of egalitarianism. The first is muscularity: males with more muscular upper bodies gave significantly less egalitarian responses on measures of SDO, SVO, worthiness and competitiveness. The second is selfperceived attractiveness, which associated significantly negatively with egalitarianism on measures of SVO and worthiness in females, and on measures of SDO, worthiness and competitiveness in males. The third is WCR, which associated significantly positively with egalitarianism on measures of SVO and competitiveness in males. In multiple regression models for predicting male egalitarianism, muscularity and SP attractiveness each explained significant unique variance in SDO and worthiness, and muscularity and WCR each explained significant unique variance in SVO and competitiveness.

Height was not a useful predictor of any form of egalitarianism in either sex. While this result was unsurprising in the case of females, it was contrary to the prediction made for males. It may be the case, as has been suggested elsewhere (von Rueden et al., 2008), that compared to muscularity, height was a relatively unimportant aspect of male formidability in ancestral environments. If short but muscular males were more likely to prevail over tall but skinny rivals, then perhaps being tall was not in itself a sufficient justification for being inegalitarian.

Contrary to predictions, WHR and VHI were not significant predictors of female egalitarianism. This was surprising, given that these traits have been linked to female attractiveness in previous studies and that SP attractiveness was a fairly good predictor of 
female egalitarianism in the current study. However, it should be noted that WHR and VHI were both uncorrelated with SP attractiveness among females in the current study. Perhaps female participants based their self-assessments on some aspect of their appearance other than bodily sex-typicality (e.g., facial attractiveness), or were simply flawed evaluators of their own attractiveness. This latter possibility has been suggested in another study (Brewer, Archer \& Manning, 2007) that found little correlation between self-perceived and anthropometrically-assessed attractiveness in females.

As predicted, we found some evidence of higher egalitarianism in females: on three of four outcome variables, female scores were significantly more egalitarian than those of males. These sex differences were not massive, but they were fairly consistent across outcome variables, and consistent with most previous studies on sex differences in egalitarianism (Croson \& Gneezy, 2009).

Results of the current study are also consistent with a previous study (Sell et al., 2009), which found that male strength and male/female self-perceived attractiveness correlated positively with the sense that one is entitled to better treatment than others, a concept that is similar to inegalitarianism. Sell et al. (2009) also found that male strength, and female (and to a lesser extent, male) self-perceived attractiveness, correlated positively with anger-proneness. To the extent that anger-proneness involves a tendency to promote unequal outcomes via the initiation of conflict, results of the current study seem to complement those results as well. In addition to being consistent with Sell et al. (2009), the current study also makes contributions that are different than those of that study, in that it examines egalitarianism extensively and directly, and utilizes a very different set of predictors (e.g. composite muscularity, anthropometric measures of attractiveness).

In future work, it would be interesting to explore the extent to which muscularity and attractiveness increase inegalitarianism, not only in terms of preferences but in terms of 
behavior as well. Some status-enhancing traits might enable an individual not just to benefit from inegalitarian social systems, but also to fare better from inegalitarian behavior in social interactions. For example, if relatively formidable individuals had less to fear in terms of being punished for inequitable behavior, then they may be more likely to engage in such behavior.

We should mention one potential complication with the hypothesis that egalitarianism will be lower in males with more masculine body shapes (e.g. greater muscularity, lower WCR). Such traits are regulated developmentally by testosterone, and testosterone, as noted in the introduction, has shown no clear relationship with egalitarian behavior in the ultimatum game. Testosterone associates positively with status-seeking behaviour (Burnham, 2007), and sometimes, somewhat paradoxically, the best way to attain status may be to behave in an egalitarian manner (e.g., to generously share one's resources). In such cases, testosterone (and associated traits) might actually relate positively to egalitarianism.

It should also be noted that because we could not test for causation in any of the relationships we demonstrated, many of our assumptions about causation could be reversed or otherwise wrong. For example, perhaps people who are more egalitarian spend less time cultivating their physical appearance, or males who are more inegalitarian spend more time lifting weights (although muscularity is heritable [Frederick \& Haselton, 2007]). While our results are a step in the direction of demonstrating the causal links that we have proposed, these links could be confirmed only through carefully designed experimental work.

Egalitarianism appears to have a large impact on one's political orientation and approach to social issues such as civil rights (Pratto, Sidanius, Stallworth \& Malle, 1994). Egalitarianism is also relevant to understanding individual positions in debates about how public goods such as health care and welfare benefits should be distributed, how much the wealthy should be taxed, and whether lucrative industries should be regulated. In attempting 
to understand the sources of egalitarian attitudes and their impact on social policy, most analysts would not consider the possibility that individual characteristics such as muscularity and attractiveness might be significant factors. The results presented above suggest that this lack of consideration could be a significant oversight. Given egalitarianism's central relevance in social life, we should strive to understand as much as we can about it, including how it may have been shaped by our evolutionary past.

\section{Acknowledgements}

We gratefully acknowledge the contributions of Orsolya Zsofia Bote and two anonymous reviewers.

\section{References}

Baron-Cohen, S. (2008). The evolution of brain mechanisms for social behavior. In C.

Crawford \& D. Krebs (Eds.), Foundations of Evolutionary Psychology, (pp. 331-352). New York: Lawrence Erlbaum.

Brewer, G., Archer, J. \& Manning, J. (2007). Physical attractiveness: The objective ornament and subjective self-ratings. Journal of Evolutionary Psychology, 5, 29-38.

Brown, W.M., Price, M.E., Kang, J., Pound, N., Zhao, Y., \& Yu, H. (2008). Fluctuating asymmetry and preferences for sex-typical bodily characteristics. Proceedings of the National Academy of Sciences, USA, 105, 12938-12943.

Burnham, T.C. (2007). High-testosterone men reject low ultimatum game offers. Proceedings of the Royal Society B: Biological Sciences, 274, 2327-2330.

Case, A., \& Paxson, C. (2008). Stature and status: Height, ability, and labor market outcomes. Journal of Political Economy, 116, 499-532.

Croson, R., \& Gneezy, U. (2009). Gender differences in preferences. Journal of Economic 
Literature, 47, 448-474.

Darwin, C. (1871/1981). The descent of man, and selection in relation to sex. Princeton, NJ: Princeton University Press.

Eckel, C.C., \& Grossman, P.J. (2002). Sex differences and statistical stereotyping in attitudes toward financial risk. Evolution and Human Behavior, 23, 281-295.

Eisenegger, C., Naef, M., Snozzi, R., Heinrichs, M. \& Fehr, E. (2010). Prejudice and truth about the effect of testosterone on human bargaining behaviour. Nature, 463, 356359.

Fan, J., Liu, F. Wu, J. \& Dai, W. (2004). Visual perception of female physical attractiveness. Proceedings of the Royal Society B: Biological Sciences, 271, 347-352.

Frederick, D.A., \& Haselton, M.G. (2007). Why is muscularity sexy? Tests of the fitness indicator hypothesis. Personality and Social Psychology Bulletin, 33, 1167-1183.

Gangestad, S.W., \& Thornhill, R. (2003). Facial masculinity and fluctuating asymmetry. Evolution and Human Behavior, 24, 231-241.

Grammer, K., Fink, B., Møller, A.P., \& Thornhill, R. (2003). Darwinian aesthetics: Sexual selection and the biology of beauty. Biological Reviews, 78, 385-407.

Houston, J.M., Harris, P., McIntire, S., \& Francis, D. (2002). Revising the Competitiveness Index using factor analysis. Psychological Reports, 90, 31-34.

Kunovich, S., \& Slomczynski, K.M. (2007). Systems of distribution and a sense of equity: A multilevel analysis of meritocratic attitudes in post-industrial societies. European Sociological Review, 23, 649-663.

Maisey, D. M., Vale, E. L. E., Cornelissen, P. L., \& Tovee, M. J. (1999). Characteristics of male attractiveness for women. Lancet, 353, 1500.

Messick, D.M., \& McClintock, C.G. (1968). Motivational bases of choice in experimental games. Journal of Experimental Social Psychology, 4, 1-25. 
Mulford, M., Orbell, J., Shatto, C., \& Stockard, J. (1998). Physical attractiveness, opportunity, and success in everyday exchange. American Journal of Sociology, 103, $1565-1592$.

Polak, M. (Ed.). (2003). Developmental instability: Causes and consequences. New York: Oxford University Press.

Pratto, F., Sidanius, J., \& Levin, S. (2006). Social dominance theory and the dynamics of intergroup relations: Taking stock and looking forward. European Review of Social Psychology, 17, 271-320.

Pratto, F., Sidanius, J., Stallworth, L.M., \& Malle, B.F. (1994). Social dominance orientation: A personality variable predicting social and political attitudes. Journal of Personality and Social Psychology, 67, 741-763.

Ritzman, R.L., \& Tomaskovic-Devey, D. (1992). Life chances and support for equality and equity as normative and counternormative distribution rules. Social Forces, 70, 745763.

Sell, A., Tooby, J., \& Cosmides, L. (2009). Formidability and the logic of human anger. Proceedings of the National Academy of Sciences, USA, 106, 15073-15078.

Sidanius, J., \& Pratto, F. (1999). Social dominance: An intergroup theory of social hierarchy and oppression. New York: Cambridge University Press.

Singh, D. (1993). Adaptive significance of female physical attractiveness: Role of waist-tohip ratio. Journal of Personality and Social Psychology, 65, 292-307.

Singh, D. (2002). Female mate value at a glance: Relationship of waist to hip ratio to health, fecundity and attractiveness. Neuroendocrinology Letters, 23(Suppl 4), 81-91.

Solnick, S.J., \& Schweitzer, M. (1999). The influence of physical attractiveness and gender on ultimatum game decisions. Organizational Behavior and Human Decision Processes, 79, 199-215. 
Solnick, S.J. (2001). Gender differences in the ultimatum game. Economic Inquiry, 39, 189200.

Swami, V., \& Tovee, M. J. (2005). Male physical attractiveness in Britain and Malaysia: A cross-cultural study. Body Image, 2, 383-393.

Takahashi, C.T., Yamagishi, S.T., Tanida, S., Kiyonari, T., \& Kanazawa, S. (2006). Attractiveness and cooperation in social exchange. Evolutionary Psychology, 4, 300314.

$\mathrm{TC}^{2}$ (2010). Information about scanner accuracy downloaded from manufacturer's website, http://www.tc2.com/index_3dbodyscan.html, on 24 November 2010.

Trivers, R.L. (1972). Parental investment and sexual selection. In B. Campbell (Ed.), Sexual selection and the descent of man, 1871-1971 (pp. 136-179). Chicago, IL: Aldine.

Van Lange, P.A.M., Otten, W., De Bruin, E.M., \& Joireman, J.A. (1997). Development of prosocial, individualistic, and competitive orientations: Theory and preliminary evidence. Journal of Personality and Social Psychology, 73, 733-746.

Von Rueden, C., Gurven, M., \& Kaplan, H. (2008). The multiple dimensions of male social status in an Amazonian society. Evolution and Human Behavior, 29, 402-415.

Zaatari, D., \& Trivers, R. (2007). Fluctuating asymmetry and behavior in the ultimatum game in Jamaica. Evolution and Human Behavior, 28, 223-227.

Zak, P.J., Kurzban, R., Park, J-W., Ahmadi, S., Swerdloff, R.S., Efremidze, L., Redwine, K., Morgan, K., \& Matzner, W. (2009). Testosterone administration decreases generosity in the ultimatum game. Public Library of Science ONE, e8330. doi:10.1371/journal.pone.0008330 
Table 1: Summary of Intercorrelations, Means, and Standard Deviations for All Continuous Study Variables

Table 2: Multiple Regression of Three Male Egalitarianism Measures on Predictors

Table 3: Logistic Regression Analysis of Relationships Between Social Value Orientation and Predictors 


\begin{tabular}{|c|c|c|c|c|c|c|c|c|c|c|c|}
\hline Measure & 1 & 2 & 3 & 4 & 5 & 6 & 7 & 8 & 9 & $M$ & $S D$ \\
\hline 1. Muscularity & - & .05 & $.88 * * *$ & $.55 * * *$ & $.48 * * *$ & $.23 *$ & -.17 & $<.01$ & .11 & -1.69 & 2.42 \\
\hline 2. SP attractiveness & -.08 & - & $<.01$ & -.01 & .04 & .13 & .14 & $.30 * *$ & .20 & 6.10 & 1.20 \\
\hline 3. VHI & $.77 * * *$ & $-.31 *$ & - & $.53 * * *$ & $.60 * * *$ & -.05 & -.06 & -.01 & .04 & 27.91 & 4.55 \\
\hline 4. WHR & $.58 * * *$ & -.07 & $.63 * * *$ & - & $.65 * * *$ & -.12 & -.10 & -.15 & -.01 & 0.71 & 0.04 \\
\hline 5. WCR & $.23 *$ & -.22 & $.61 * * *$ & $67 * * *$ & - & .08 & -.05 & -.03 & .11 & 0.79 & 0.05 \\
\hline 6. Height & -.02 & .04 & $-.27 *$ & -.13 & .05 & - & -.20 & .09 & .19 & 166.18 & 6.53 \\
\hline 7. $\mathrm{SDO}$ & $.29 *$ & $.28 *$ & .10 & .06 & -.08 & .08 & - & $.49 * * *$ & $.22 *$ & 3.03 & 1.32 \\
\hline 8. Worthiness & $.31 * *$ & $.37 * *$ & .08 & .12 & -.11 & -.12 & $.31 *$ & - & $.25^{*}$ & 3.74 & 1.72 \\
\hline 9. Competitiveness & $.24^{*}$ & $.25^{*}$ & -.04 & -.02 & $-.32 * *$ & .05 & $.34 * *$ & $.39 * *$ & - & 5.60 & 1.71 \\
\hline$M$ & 1.87 & 6.17 & 28.39 & 0.81 & 0.78 & 177.13 & 3.49 & 4.31 & 6.32 & & \\
\hline$S D$ & 2.01 & 1.05 & 3.72 & 0.05 & 0.04 & 6.71 & 1.54 & 1.87 & 1.69 & & \\
\hline
\end{tabular}

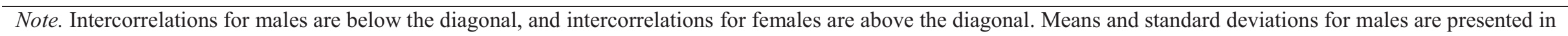
the horizontal rows, and means and standard deviations for females are presented in the vertical columns.

$* p<.05, * * p<.01, * * * p<.001$. 
Egalitarianism measure

\begin{tabular}{|c|c|c|c|c|c|c|}
\hline \multirow[b]{2}{*}{ Predictor } & \multicolumn{2}{|c|}{ SDO } & \multicolumn{2}{|c|}{ Worthiness } & \multicolumn{2}{|c|}{ Competitiveness } \\
\hline & $\beta$ & $p$ & $\beta$ & $p$ & $\beta$ & $p$ \\
\hline Muscularity & .34 & .007 & .33 & .006 & .33 & .006 \\
\hline SP attractiveness & .28 & .020 & .36 & .003 & .18 & .078 \\
\hline WCR & -.11 & .214 & -.18 & .080 & -.37 & .003 \\
\hline Height & .11 & .205 & -.14 & .135 & .09 & .238 \\
\hline
\end{tabular}




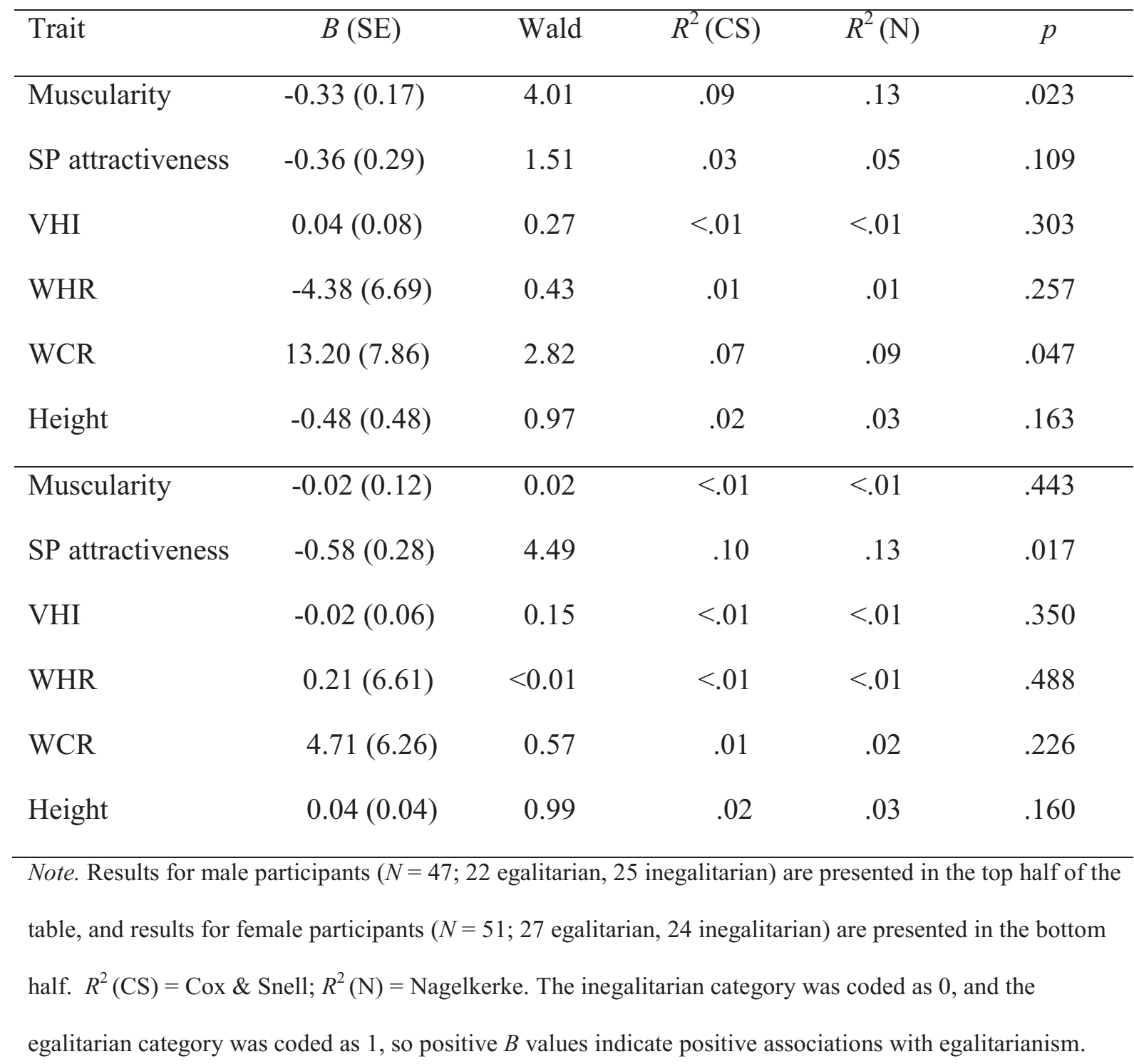

